\title{
Results of Urine Culture and Antimicrobial Sensitivity Tests According to the Voiding Method Over 10 Years in Patients with Spinal Cord Injury
}

\author{
Kyoung Ho Ryu, Yun Beom Kim, Seung Ok Yang, Jeong Kee Lee, Tae Young Jung \\ Department of Urology, Seoul Veterans Hospital, Seoul, Korea
}

Purpose: We studied the results of urine cultures and antimicrobial sensitivity tests according to the voiding method used by spinal cord injury (SCI) patients over a recent 10-year period.

Materials and Methods: We retrospectively analyzed 1,236 urine samples and their antimicrobial sensitivity tests for 112 patients who had used only one voiding method between January 2000 and December 2009. The voiding methods were classified into four groups: clean intermittent catheterization (CIC), suprapubic catheterization, urethral Foley catheter, and spontaneous voiding.

Results: Of the 1,236 urine samples, 925 (74.8\%) were positive and $279(30.2 \%)$ had more than one bacteria. The CIC group showed the lowest rate of bacteriuria, colony counts, and polymicrobial infection $(\mathrm{p}<0.001)$. Causative organisms were mostly Gram-negative bacteria (84\%), including Pseudomonas aeruginosa (22.9\%), Escherichia coli $(21.1 \%)$, Klebsiella species (6.7\%), and Citrobacter species (6.3\%). The rate of Gram-positive bacterial infection was $13.6 \%$, and major pathogenic organisms were Streptococcus species (8.6\%) and Staphylococcus species (2.6\%). Major pathogenic organisms and the results of antimicrobial sensitivity tests differed according to the voiding method.

Conclusions: Although the patient's condition and preferences are important when choosing the method of bladder management, CIC is the best voiding method for reducing urinary tract infections in SCI patients. When immediate use of antibiotics is needed for treatment of urinary tract infections, an appropriate antibiotic can be chosen according to the voiding method on the basis of our study and can be administered before the results of an antimicrobial sensitivity test are available.

Key Words: Bacteriuria; Microbial sensitivity tests; Spinal cord injuries; Urinary tract infections

This is an Open Access article distributed under the terms of the Creative Commons Attribution Non-Commercial License (http://creativecommons.org/licenses/by-nc/3.0) which permits unrestricted non-commercial use, distribution, and reproduction in any medium, provided the original work is properly cited.

\author{
Article History: \\ received 8 April, 2011 \\ accepted 25 April, 2011
}

Corresponding Author:

Tae Young Jung

Department of Urology, Seoul Veterans Hospital, 6-2, Dunchon 2-dong,

Gangdong-gu, Seoul 134-791, Korea

TEL: +82-2-2225-1739

FAX: +82-2-484-4604

E-mail: urodoct@hotmail.com

\section{INTRODUCTION}

Spinal cord injury (SCI) patients have many urological complications, including urinary tract infection (UTI), bladder stone, renal stone, hydronephrosis, and vesicoureteral reflux [1,2]. Of these complications, recurrent UTI is a major cause of morbidity, such as upper urinary tract deterioration [3]. Therefore, prevention and proper manage- ment of UTIs in SCI patients are very important.

Voiding methods for SCI patients with neurogenic bladder include clean intermittent catheterization (CIC), suprapubic catheterization (SPC), urethral Foley catheter (UF), and condom drainage. However, these voiding methods increase the risk of catheter-related recurrent UTIs that require multiple courses of antibiotic therapy. Eventually, the risk of antibiotic-resistant organisms is increased. 
Therefore, preventing the occurrence of antibiotic-resistant organisms through the use of suitable antibiotics is a major issue.

There are many studies about urologic complications and UTIs of SCI patients, but studies about UTIs according to the method of bladder drainage are rare. In the present study, therefore, we investigated the results of urine cultures and antimicrobial sensitivity tests according to the method of bladder drainage used by SCI patients over a recent 10-year period.

\section{MATERIALS AND METHODS}

From January 2000 to December 2009, 112 SCI patients were included in this study. We retrospectively reviewed the medical records of the patients to analyze the results of urine cultures and antimicrobial sensitivity tests. The age distribution was comparable for all four groups and ranged from 25 to 80 years with a mean age of 55.9 years. The male:female ratio was 111:1 (99.1\%:0.9\%). All patients had used only one voiding method (no change in voiding method) during the study period. The patients were classified into four groups as follows: CIC ( $n=41), \mathrm{SPC}(\mathrm{n}=34), \mathrm{UF}$ $(\mathrm{n}=9)$, and spontaneous voiding $(\mathrm{SV} ; \mathrm{n}=28)$.

Of a total of 1,353 urine samples, we excluded 117 urine samples that were considered unresolved bacteriuria. A total of 1,236 urine samples were finally analyzed in our study. Of these 1,236 urine samples, 898 (72.7\%) were obtained from patients with symptoms such as fever, flank pain, suprapubic discomfort, cloudy urine, and foul odor, and $338(27.3 \%)$ were collected in the case of regular periodic follow-up.

Urine samples were collected by catheterization or by using the clean-catch technique for patients able to void spontaneously. Urine specimens collected by catheterization were obtained by aseptically aspirating the clamped and disinfected catheter with a sterile syringe after the catheter change or at the time of intermittent catheterization.

All specimens were cultured and isolates were identified in the routine laboratory. The minimum viable count for diagnosis of bacteriuria was $10^{3} \mathrm{CFU} / \mathrm{ml}$.

Antimicrobial sensitivity tests were performed on bacteria considered significant, and the results were stratified by voiding method group. The antibiotics included in our study were penicillin, ampicillin, Augmentin, cefazolin, ce- foxitin, cefotetan, cefuroxime, ceftazidime, ceftriaxone, cefepime, ofloxacin, ciprofloxacin, levofloxacin, gentamicin, tobramycin, amikacin, piperacillin, piperacillin/tazobactam, imipenem, meropenem, vancomycin, trimethoprim-sulfamethoxazole, and tetracycline.

The method of statistical analysis used was the chi-square test (with Fisher's exact test) using SPSS ver. 15.0 (SPSS Inc., Chicago, IL, USA). A p-value of $<0.05$ was considered to be statistically significant.

\section{RESULTS}

\section{Results of urine cultures}

1) Positive urine culture: Of the 1,236 samples, 925 (74.8\%) were positive. In the CIC group, 366 (69.8\%) urine samples were positive and this result was significantly lower than in the other groups $(\mathrm{p}<0.001)$ (Table 1).

2) Colony counts: Colony counts of isolated bacteria are presented in Table 2. The CIC group showed lower colony counts than did the other groups $(\mathrm{p}<0.001)$.

3) Polymicrobial infection: Polymicrobial infection was common. Among all (925) positive urine samples, multiple species were identified in $279(30.2 \%)$ urine samples. In the CIC group, 2 species were isolated in 53 (14.5\%) urine samples and 3 species were isolated in $2(0.5 \%)$ urine samples. These results were significantly lower than in the other groups ( $<<0.001)$ (Table 3).

4) The major organisms in the urine samples: The vast majority of cases of bacteriuria were caused by gram-negative bacteria ( $84 \%)$. Major pathogenic gram-negative bacteria included Pseudomonas aeruginosa (22.9\%) and Escherichia coli (E. coli, 21.1\%), followed by Klebsiella spe-

TABLE 1. Positive urine cultures according to voiding method

\begin{tabular}{lcrrr}
\hline & $\begin{array}{c}\text { Sterile } \\
\text { cultures (\%) }\end{array}$ & $\begin{array}{c}\text { Positive } \\
\text { cultures (\%) }\end{array}$ & Total (\%) & p-value \\
\hline CIC & $158(30.2)$ & $366(69.8)$ & $524(100)$ & $<0.001$ \\
SPC & $74(17.7)$ & $343(82.3)$ & $417(100)$ & \\
UF & $22(22.4)$ & $76(77.6)$ & $98(100)$ & \\
SV & $57(28.9)$ & $140(71.1)$ & $197(100)$ & \\
\hline
\end{tabular}

CIC: clean intermittent catheterization, SPC: suprapubic catheterization, UF: urethral Foley catheter, SV: spontaneous voiding,

${ }^{\mathrm{a}}$ : analyzed by chi-square test

TABLE 2. Colony counts of the positive urine cultures

\begin{tabular}{|c|c|c|c|c|c|c|}
\hline $\begin{array}{l}\text { Colony counts } \\
\text { (CFU/ml) }\end{array}$ & $10^{3}(\%)$ & $10^{4}(\%)$ & $10^{5}(\%)$ & $10^{6} \leq(\%)$ & Total (\%) & $\mathrm{p}$-value ${ }^{\mathrm{a}}$ \\
\hline CIC & $2(0.5)$ & $182(49.7)$ & $129(35.2)$ & $53(14.5)$ & $366(100)$ & $<0.001$ \\
\hline SPC & $2(0.6)$ & $126(36.7)$ & $116(33.8)$ & 99 (28.9) & $343(100)$ & \\
\hline $\mathrm{UF}$ & $0(0.0)$ & $25(32.9)$ & $27(35.5)$ & $24(31.6)$ & 76 (100) & \\
\hline SV & $0(0.0)$ & $51(36.4)$ & $51(36.4)$ & $38(27.1)$ & $140(100)$ & \\
\hline
\end{tabular}

CIC: clean intermittent catheterization, SPC: suprapubic catheterization, UF: urethral Foley catheter, SV: spontaneous voiding, ${ }^{\text {a }}$ analyzed by chi-square test 
TABLE 3. Isolates of urine cultures according to voiding method

\begin{tabular}{lrrrrr}
\hline Isolates & \multicolumn{1}{c}{$1(\%)$} & \multicolumn{1}{c}{$2(\%)$} & $3(\%)$ & Total $(\%)$ & p-value $^{\mathrm{a}}$ \\
\hline CIC & $311(85.0)$ & $53(14.5)$ & $2(0.5)$ & $366(100)$ & $<0.001$ \\
SPC & $190(55.4)$ & $148(43.1)$ & $5(1.5)$ & $343(100)$ & \\
UF & $45(59.2)$ & $30(39.5)$ & $1(1.3)$ & $76(100)$ & \\
SV & $100(71.4)$ & $40(28.6)$ & $0(0.0)$ & $140(100)$ & \\
\hline
\end{tabular}

CIC: clean intermittent catheterization, SPC: suprapubic catheterization, UF: urethral Foley catheter, SV: spontaneous voiding,

${ }^{\mathrm{a}}$ : analyzed by chi-square test

TABLE 4. Major causative organisms (Top 1-10)

\begin{tabular}{|c|c|c|c|c|}
\hline & $\mathrm{CIC}(\%)$ & $\mathrm{SPC}(\%)$ & $\mathrm{UF}(\%)$ & $\mathrm{SV}(\%)$ \\
\hline $\begin{array}{l}\text { Pseudomonas } \\
\text { aeruginosa }\end{array}$ & $56(14.0)$ & $158(34.6)$ & $21(21.2)$ & 49 (27.5) \\
\hline Escherichia coli & $137(34.3)$ & 54 (11.8) & $27(27.3)$ & $43(24.2)$ \\
\hline $\begin{array}{l}\text { Streptococcus } \\
\text { species }\end{array}$ & $36(9.0)$ & $52(11.4)$ & $3(3.0)$ & $16(9.0)$ \\
\hline $\begin{array}{l}\text { Klebsiella } \\
\text { species }\end{array}$ & 47 (11.8) & $15(3.3)$ & $13(13.1)$ & $8(4.5)$ \\
\hline $\begin{array}{l}\text { Citrobacter } \\
\text { species }\end{array}$ & $38(9.5)$ & $28(6.1)$ & $6(6.1)$ & $6(3.4)$ \\
\hline $\begin{array}{l}\text { Providencia } \\
\text { species }\end{array}$ & $10(2.5)$ & $55(12.1)$ & $2(2.0)$ & $11(6.2)$ \\
\hline $\begin{array}{l}\text { Serratia } \\
\quad \text { marcescens }\end{array}$ & $22(5.5)$ & $25(5.5)$ & $7(7.1)$ & $5(2.8)$ \\
\hline $\begin{array}{l}\text { Acinetobacter } \\
\text { species }\end{array}$ & $18(4.5)$ & $16(3.5)$ & $4(4.0)$ & $12(6.7)$ \\
\hline $\begin{array}{c}\text { Morganella } \\
\text { morganii }\end{array}$ & $7(1.8)$ & $25(5.5)$ & $9(9.1)$ & $6(3.4)$ \\
\hline Proteus species & $5(1.3)$ & $14(3.1)$ & $5(5.1)$ & $10(5.6)$ \\
\hline $\begin{array}{l}\text { Staphylococcus } \\
\text { species }\end{array}$ & $24(6.0)$ & $14(3.1)$ & $2(2.0)$ & $12(6.7)$ \\
\hline Total & $400(100)$ & $510(100)$ & $130(100)$ & $178(100)$ \\
\hline
\end{tabular}

CIC: clean intermittent catheterization, SPC: suprapubic catheterization, UF: urethral Foley catheter, SV: spontaneous voiding

cies (6.7\%), Citrobacter species (6.3\%), Providencia species (6.3\%), Serratia marcescens $(4.8 \%)$, Acinetobacter species (4.0\%), Morganella morganii (3.8\%), and Proteus species $(2.7 \%)$. Of the isolates, $13.6 \%$ were gram-positive bacteria, mainly Streptococcus species (8.6\%) and Staphylococcus species $(2.6 \%)$.

The most commonly isolated pathogens in each group were $E$. coli in the CIC and UF groups and Pseudomonas aeruginosa in the SPC and SV groups, respectively (Table 4).

\section{Results of antimicrobial sensitivity tests}

In the antimicrobial sensitivity tests, vancomycin, meropenem, and imipenem showed very high (more than 90\%) sensitivity in all groups. Other antibiotics that showed high sensitivity in each group were as follows. Amikacin (84.5\%), cefepime $(83.7 \%)$, piperacillin/tazobactam $(73.9 \%)$, ofloxacin $(70.3 \%)$, ceftazidime $(66.0 \%)$, cefotetan $(62.1 \%)$, Augmentin $(61.3 \%)$, and tobramycin $(61.3 \%)$ showed high sen-
TABLE 5. Result of antimicrobial sensitivity tests according to voiding method

\begin{tabular}{|c|c|c|c|c|}
\hline & CIC (\%) & $\mathrm{SPC}(\%)$ & $\mathrm{UF}(\%)$ & $\mathrm{SV}(\%)$ \\
\hline Penicillin & 49.2 & 67.1 & 33.3 & 23.1 \\
\hline Ampicillin & 9.5 & 13.3 & 6.7 & 18.3 \\
\hline Augmentin & 61.3 & 33.7 & 45.7 & 44.1 \\
\hline Cefazolin & 52.6 & 26.5 & 36.1 & 43.2 \\
\hline Cefoxitin & 59.2 & 48.7 & 43.8 & 59.7 \\
\hline Cefotetan & 62.1 & 47.6 & 77.3 & 65.5 \\
\hline Cefuroxime & 34.4 & 23.4 & 34.6 & 47.7 \\
\hline Ceftazidime & 66.0 & 54.3 & 64.4 & 74.6 \\
\hline Ceftriaxone & 50.6 & 36.5 & 42.1 & 51.3 \\
\hline Cefepime & 83.7 & 73.2 & 76.6 & 80.3 \\
\hline Ofloxacin & 70.3 & 59.5 & 87.5 & 54.5 \\
\hline Ciprofloxacin & 33.9 & 41.8 & 50.0 & 36.1 \\
\hline Levofloxacin & 36.3 & 38.3 & 57.1 & 36.7 \\
\hline Gentamicin & 58.2 & 55.9 & 50.5 & 49.4 \\
\hline Tobramycin & 61.3 & 59.2 & 70.5 & 56.9 \\
\hline Amikacin & 84.5 & 74.0 & 86.0 & 72.2 \\
\hline Piperacillin & 36.4 & 50.5 & 45.1 & 47.0 \\
\hline $\begin{array}{r}\text { Piperacillin/ } \\
\text { tazobactam }\end{array}$ & 73.9 & 62.4 & 74.0 & 77.7 \\
\hline Imipenem $^{\mathrm{a}}$ & 95.1 & 94.4 & 92.2 & 96.5 \\
\hline Meropenem $^{\mathrm{a}}$ & 93.2 & 95.0 & 100 & 94.8 \\
\hline Vancomycin $^{a}$ & 100 & 96.6 & 100 & 100 \\
\hline $\begin{array}{l}\text { Trimethoprim- } \\
\text { sulfamethoxazole }\end{array}$ & 49.5 & 53.9 & 54.2 & 42.4 \\
\hline Tetracycline & 30.1 & 23.5 & 25.0 & 31.1 \\
\hline
\end{tabular}

CIC: clean intermittent catheterization, SPC: suprapubic catheterization, UF: urethral Foley catheter, SV: spontaneous voiding,

${ }^{\mathrm{a}}$ : showed very high (more than $90 \%$ ) sensitivity in all groups

sitivity in the CIC group. In the SPC group, amikacin (74.0\%), cefepime $(73.2 \%)$, penicillin $(67.1 \%)$, and piperacillin/tazobactam (62.4\%) had high sensitivity. In the UF group, ofloxacin $(87.5 \%)$, amikacin (86.0\%), cefotetan $(77.3 \%)$, cefepime (76.6\%), piperacillin/tazobactam (74.0\%), tobramycin (70.5\%), and ceftazidime (64.4\%) showed high sensitivity. Cefepime (80.3\%), piperacillin/tazobactam (77.7\%), ceftazidime (74.6\%), amikacin $(72.2 \%)$, and cefotetan $(65.5 \%)$ showed high sensitivity in the SV group (Table 5).

\section{DISCUSSION}

The development of voiding methods for patients with SCI has decreased urologic complications and the mortality rate. Despite these improvements, however, UTI is still a major cause of morbidity in SCI patients.

The definitions for significant bacteriuria in SCI patients are controversial. In a study of patients with SCI, Dedeić-Ljubović and Hukić considered significant bacteriuria to be $\geq 10^{4} \mathrm{CFU} / \mathrm{ml}$ [4]. In another study, Menon and Tan reported that all positive urine cultures had $\geq 10^{5}$ CFU/ml [5]. These thresholds lack sensitivity, however. The National Institute on Disability and Rehabilitation Research (NIDRR) Consensus Statement recommended 
the following uropathogen colony count criteria for the diagnosis of significant bacteriuria in persons with SCI: (1) $\geq 10^{2} \mathrm{CFU} / \mathrm{ml}$ for catheter specimens from individuals on intermittent catheterization, (2) $\geq 10^{4} \mathrm{CFU} / \mathrm{ml}$ for cleanvoid specimens from catheter-free males using condom collection devices, and (3) any detectable concentration of uropathogens from indwelling catheters or suprapubic aspirates because the vast majority of patients with an indwelling catheter and low-level bacteriuria showed an increase to greater than $10^{5} \mathrm{CFU} / \mathrm{ml}$ within a short period of time [6]. In our study, more than $10^{3} \mathrm{CFU} / \mathrm{ml}\left(\geq 10^{3} \mathrm{CFU} /\right.$ $\mathrm{ml}$ ) of uropathogens were evaluated; this threshold is identical to that of most Korean hospitals. According to the definition of the NIDRR, all of the positive urine culture results were significant bacteriuria.

Our study reported a positive urine culture rate of $74.8 \%$. In another study of patients with SCI, Dedeić-Ljubović and Hukić reported that $87.3 \%$ of samples had a positive urine culture [4]. This modest difference may be because our study population included some patients who were seen for regular periodic follow-up.

In non-SCI patients, more than $10^{5} \mathrm{CFU} / \mathrm{ml}$ is considered significant bacteriuria. Our results showed that a considerable portion of specimens $(41.9 \%)$ had colony counts of less than $10^{5} \mathrm{CFU} / \mathrm{ml}$. This suggests that a low colony count of a specimen is an important aspect in the diagnosis of UTI in SCI patients.

Most bacteriuria in short-term catheterization is of a single organism, whereas patients catheterized for longer than 1 month will usually demonstrate a polymicrobial flora caused by a wide range of gram-negative and grampositive bacterial species. Such specimens commonly have two to four bacterial species, each at concentrations of $10^{5}$ $\mathrm{CFU} / \mathrm{ml}$ or more. Some may have up to six to eight species at that concentration. This phenomenon is due to an incidence of new episodes of bacteriuria approximately every 2 weeks and the ability of these strains to persist for weeks and months in the catheterized urinary tract [7]. The rate of polymicrobial infection was $30.2 \%$ in our study, and the CIC group (14.5\%) showed a significantly lower rate than did the other groups. In another study of SCI patients, Dedeić-Ljubović and Hukić reported a rate of polymicrobial infection of $44.9 \%$ and a lower rate $(40.8 \%)$ in the CIC group [4]. On the other hand, in studies of UTI in non-SCI patients, the rate of polymicrobial infection ranged from $3.5 \%$ to $21.8 \%$ and was lower than in the SCI patients [8-12].

In 1966, Guttmann and Frankel recommended sterile intermittent catheterization for the initial management of neurogenic bladder in SCI patients [13]. In 1972, Lapides et al reported that CIC could prevent UTI in patients with incomplete bladder drainage and neurogenic bladder [14]. In many previous studies of SCI patients, CIC showed a low risk of urologic complications $[4,15,16]$. In the present study, the CIC group showed the lowest rate of positive urine cultures, colony counts, and number of isolates.

The common causative organisms in uncomplicated UTI are E. coli (34.4\% to $67.0 \%)$, followed by Enterococcus,
Pseudomonas, Enterobacter, Klebsiella, and Staphylococcus [8-12]. The major organisms causing UTI in patients with SCI differ from those in patients with intact spinal cords in etiology, complexity, and antimicrobial susceptibility and are influenced by the type and duration of catheterization. In most studies of UTI in patients with SCI or indwelling catheter, interestingly, E. coli was isolated in less than $20 \%$ (4.3\% to $19 \%$ ) of patients and Pseudomonas aeruginosa, Proteus mirabilis (P. mirabilis), or Enterococcus faecalis were more common among SCI patients than among patients with intact spinal cords. Other common organisms were Klebsiella pneumoniae, Providencia stuartii, Morganella species, Acinetobacter species, Serratia species, Staphylococcus, and Candida species [4,5,17-20]. Especially, urease-splitting organisms including Klebsiella pneumonia, Proteus mirabilis, Pseudomonas aeruginosa, and Providencia stuartii were isolated at a relatively high rate of cultures in patients with SCI or indwelling catheters. Mobley and Warren reported that $86 \%$ of all specimens were urease-positive bacterial species, and major organisms were $P$. mirabilis and $M$. morganii, and these species made up over half of the specimens [21]. In our results, ureasplitting organisms were isolated in $62 \%$ of cultures, and the major organisms were Pseudomonas species and Klebsiella species.

E. coli, a commensal organism of the bowel and perineum, was most common in the CIC and UF groups, even though Pseudomonas species were the most common bacteria in our study. This result suggests that $E$. coli is strongly associated with the periurethra adjacent to the perineum. Munir et al reported that $E$. coli was the most common organism causing bacteriuria in catheterized patients and that there was a significant association between periurethral colonization and subsequent bacteriuria [22]. Also, Schlager et al reported that the origin of $E$. coli isolated from the urine of children with neurogenic bladder receiving CIC was the periurethra [23].

In the treatment of UTIs, selection of antibiotics is a major concern. First-line antibiotics should be chosen in view of effectiveness and prevention of antibiotic resistance. Therefore, urologists have no choice but to use empirical antibiotics considering the antibiotic restriction policy (prefer common antibiotics to restricted antibiotics for preventing resistant bacteria) until the reports of an antimicrobial sensitivity test are available. Unfortunately, few studies have analyzed the results of antimicrobial sensitivity tests according to the voiding method used in SCI patients with UTI. Our study thus provides valuable information about first-line antibiotic treatment in SCI patients with UTI.

Our results showed a difference in antibiotic sensitivity among the groups according to the voiding method used. Vancomycin, meropenem, and imipenem showed very high (more than 90\%) sensitivity in all groups. However, these antibiotics are restricted and are considered last resort antibiotics. The initial use of these antibiotics before identification of the causative bacteria can produce resistant 
bacteria. We suggest that choosing the first-line antibiotic by considering the result of an antimicrobial sensitivity test according to the voiding method can produce an increased treatment effect and a decreased production of resistant bacteria.

This study has several limitations. First, the voiding methods of patients before 2000 could not be investigated, so the previous voiding method might have influenced the results of the urine culture and antimicrobial sensitivity test. Second, urinary calculi, vesicoureteral reflux, interval of catheter change, and previous antibiotic treatment were not investigated in our study. If these factors were additionally investigated, the relationship between voiding methods and our results could be clarified further.

In conclusion, an appropriate choice of voiding method is extremely important to prevent (recurrent) UTIs in SCI patients. Furthermore, the immediate administration of proper antibiotics according to the voiding method can produce effective treatment in SCI patients with symptomatic UTI and decrease the risk of antibiotic resistance.

\section{CONCLUSIONS}

We studied the results of urine cultures and antimicrobial sensitivity tests according to the voiding method used by SCI patients over a recent 10 -year period. CIC is generally recognized to reduce UTIs and various urological complications. We determined that the rate of positive urine cultures, the colony counts, and the number of isolates were lower in the CIC group than in the other groups. Furthermore, when immediate use of antibiotics is needed for treatment of UTI, a proper choice of antibiotics can be made according to the voiding method.

\section{Conflicts of Interest}

The authors have nothing to disclose.

\section{REFERENCES}

1. So JG, Oh DJ, Lim YS, Park WH, Shim HB. Urologic complications and management in 337 spinal cord injured patients. Korean J Urol 1997;38:1075-80.

2. Bennett CJ, Young MN, Adkins RH, Diaz F. Comparison of bladder management complication outcomes in female spinal cord injury patients. J Urol 1995;153:1458-60.

3. Kwon T, Park J, Park MC, Han JY, Kim KS. Risk factors for upper urinary tract deterioration in children with neurogenic bladder. Korean J Urol 2009;50:1248-52.

4. Dedeić-Ljubović A, Hukić M. Catheter-related urinary tract infection in patients suffering from spinal cord injuries. Bosn $J$ Basic Med Sci 2009;9:2-9.

5. Menon EB, Tan ES. Urinary tract infection in acute spinal cord injury. Singapore Med J 1992;33:359-61.

6. The prevention and management of urinary tract infections among people with spinal cord injuries. National Institute on Disability and Rehabilitation Research Consensus Statement. January 27-29, 1992. J Am Paraplegia Soc 1992;15:194-204.

7. Schaeffer AJ, Schaeffer EM. Infections of the urinary tract. In: Wein AJ, Kavoussi LR, Novick AC, Partin AW, Peters CA, editors. Campbell-Walsh urology. 9th ed. Philadelphia: Saunders; 2007;298.

8. Ko YH, Oh JS, Cho DY, Bea JH, Koh SK. Changes of causative organisms and antimicrobial sensitivity of urinary tract infection between 1979 and 2001. Korean J Urol 2003;44:342-50.

9. Ko HS, Choi DY, Han YT. A study of the changes of antibiotic sensitivity to the causative organisms of urinary tract infection for recent 5 years. Korean J Urol 1999;40:809-16.

10. Kim SW, Lee JY, Park WJ, Cho YH, Yoon MS. Antibiotic sensitivity to the causative organism of acute simple urinary tract infection. Korean J Urol 2000;41:1117-24.

11. Song HJ, Kim SJ. A study of antimicrobial sensitivity to the causative organism of urinary tract infection. Korean $J$ Urol 2005;46:68-73.

12. Ryu KH, Kim MK, Jeong YB. A recent study on the antimicrobial sensitivity of the organisms that cause urinary tract infection. Korean J Urol 2007;48:638-45.

13. Guttmann L, Frankel H. The value of intermittent catheterisation in the early management of traumatic paraplegia and tetraplegia. Paraplegia 1966;4:63-84.

14. Lapides J, Diokno AC, Silber SJ, Lowe BS. Clean intermittent self-catheterization in the treatment of urinary tract disease. $J$ Urol 1972;107:458-61.

15. Weld KJ, Dmochowski RR. Effect of bladder management on urological complications in spinal cord injured patients. J Urol 2000;163:768-72.

16. Gallien P, Nicolas B, Robineau S, Le Bot MP, Durufle A, Brissot $R$. Influence of urinary management on urologic complications in a cohort of spinal cord injury patients. Arch Phys Med Rehabil 1998;79:1206-9.

17. Jewes LA, Gillespie WA, Leadbetter A, Myers B, Simpson RA, Stower MJ, et al. Bacteriuria and bacteraemia in patients with long-term indwelling catheters--a domiciliary study. J Med Microbiol 1988;26:61-5.

18. Warren JW. Catheter-associated urinary tract infections. Int $\mathrm{J}$ Antimicrob Agents 2001;17:299-303.

19. Ahn CH, Par DH. Clinical evaluation of the urinary tract infection in spinal cord injury patient. Korean J Urol 1983;24:783-8.

20. Penders J, Huylenbroeck AA, Everaert K, Van Laere M, Verschraegen GL. Urinary infections in patients with spinal cord injury. Spinal Cord 2003;41:549-52.

21. Mobley HL, Warren JW. Urease-positive bacteriuria and obstruction of long-term urinary catheters. J Clin Microbiol 1987; 25:2216-7.

22. Munir T, Lodhi M, Hussain RM, Mubeen M. Association between periurethral colonization with uropathogens and subsequent bacteriuria in catheterized patients. J Coll Physicians Surg Pak 2009;19:169-72.

23. Schlager TA, Hendley JO, Wilson RA, Simon V, Whittam TS. Correlation of periurethral bacterial flora with bacteriuria and urinary tract infection in children with neurogenic bladder receiving intermittent catheterization. Clin Infect Dis 1999;28:346-50. 